\title{
Poder de mercado y transmisión asimétrica de precios en el mercado de hidrocarburos en Nicaragua
}

Juan Polvorosa ${ }^{1}$, Álvaro Altamirano², Gabriela Arteaga ${ }^{2}$, Eddy Gamboa², Francisco Lacayo $^{2}$, Xochilt Loásiga ${ }^{2}$, Laureen Montes ${ }^{2}$ y Gustavo Vega ${ }^{2}$

${ }^{1}$ Profesor, Departamento de Economía Aplicada, Universidad Centroamericana. Rotonda Rubén Darío 150 mts. al oeste. Apartado 69, Managua, Nicaragua. Correo electrónico: jpolvorosa@ns.uca.edu.ni.

${ }^{2}$ Estudiantes del cuarto año de la Carrera de Economía Aplicada, Universidad Centroamericana.

Recibido: mayo de 2009 / Aceptado: julio de 2009

LA INVESTIGACIÓN DESCRIBE UNA CADENA DE COMERCIALIZACIÓN DE PRODUCTOS derivados del petróleo -específicamente de diesel y gasolinas- altamente concentrada en Nicaragua, donde una empresa concentra un gran porcentaje del mercado en la fase de distribución y ventas. La regresión de nuestro modelo identificó la presencia de asimetría tanto en magnitud como en velocidad para el diesel y la gasolina súper. En términos de la velocidad de ajuste de los precios, ambos productos exhiben asimetrías, dado que los períodos de ajuste difieren entre alzas y bajas de los precios. La asimetría en la magnitud del ajuste describe una situación en la que, para ambos productos, los incrementos en los precios internacionales conllevan a un aumento más que proporcional de los precios domésticos, siendo más significativo este ajuste para el diesel. Por otro lado, las reducciones en los precios internacionales se traducen en reducciones de la misma magnitud para el diesel, no así para la gasolina, cuyo precio desciende menos que proporcionalmente al descenso experimentado en el precio internacional de la misma.

Palabras clave: precio / poder de mercado / asimetría / petróleo / hidrocarburos

\section{Introducción}

Durante los meses de agosto y septiembre de 2008, luego de que los precios del crudo alcanzaran precios históricos nunca antes vistos, los consumidores a nivel nacional siguieron muy de cerca los movimientos de los precios de los combustibles en las estaciones de servicio así como las variaciones de los precios internacionales del petróleo. En general, el publico percibía cierta disparidad en el movimiento de los precios de dichos productos; mientras el precio internacional del petróleo bajaba, los precios nacionales de los carburantes en las estaciones de servicio subían semana a semana, lo que generó 
descontento entre el público en general. Esta situación despertó, en su momento, el interés del gobierno, diputados y asociaciones de consumidores, a fin de crear un marco legal que permitiese tener un mayor control en los procesos de cálculo semanales de los precios de los combustibles que realizan las cadenas distribuidoras de dichos productos. A su vez, suscitó un debate entre autoridades del Instituto Nicaragüense de Energía (INE), especialistas en el tema y representantes de dichas compañías en torno a la pertinencia del establecimiento de algún mecanismo de control sobre los precios de los hidrocarburos. Esta disparidad o asimetría entre los movimientos del precio del petróleo y los precios nacionales de los hidrocarburos es el tema tratado en el presente artículo.

La asimetría de precios se refiere al fenómeno en el cual los cambios en los precios de los productos finales aguas abajo no se corresponden con los cambios en los precios de las materias primas aguas arriba en la cadena de valor. La asimetría de precios desafía los supuestos de la economía neoclásica en relación a la teoría del precio. Según la economía neoclásica los precios se transmiten de forma simétrica e incluyen toda la información necesaria para la óptima asignación de los recursos. Este supuesto se mantiene en mercados sin fricciones ni imperfecciones. Bajo estas estructuras, el comportamiento maximizador de beneficios fuerza a las empresas en mercados competitivos a ajustar sus precios a las nuevas condiciones de costos inmediatamente y de forma simétrica, presumiblemente. Lo contrario ocurre con la transmisión asimétrica de precios, cuando en los mercados no competitivos las empresas cargan el incremento de los costos al precio que paga el consumidor final para mantener el mismo margen de ganancias. Cuando los costos disminuyen, esta situación no se ve reflejada en una disminución de los precios. Lo anterior "implica una distribución de la riqueza distinta a la que podría obtenerse bajo simetría, porque altera la rapidez y/o la magnitud de los cambios en la riqueza asociados a cambios en el precio" (Meyer \& von Cramon-Taubade, 2004:582). La transmisión asimétrica de precios no sólo constituye un problema en la distribución de los recursos. Provoca la pérdida de eficiencia económica debido a las estructuras de mercado poco competitivas asociadas a este proceso. Debido a lo anterior, algunos legisladores de la Asamblea Nacional estudiaron en su momento la posibilidad de introducir una iniciativa de ley que permitiese restablecer un sistema de Precios de Paridad de Importación para regular los precios de los hidrocarburos, como se hacía a inicios de los años noventa ${ }^{1}$.

El presente artículo tiene por objetivo identificar y cuantificar la existencia de asimetrías en la transmisión de precios desde los mercados internacionales de hidrocarburos hasta los mercados de dichos productos en Nicaragua. Para tal fin, ejecutamos dos modelos utilizando datos semanales del Instituto Nicaragüense de Energía (INE) de los precios nacionales e internacionales de productos derivados del petróleo, específicamente diesel y gasolina súper.

Para estudiar más profundamente este fenómeno y sus implicaciones en el mercado del petróleo, se debe primero tener una idea global de la estructura de la cadena de los hidrocarburos en nuestro país. En este sentido, la sección dos de este estudio describe la cadena de comercialización de hidrocarburos en Nicaragua, así como los principales actores que toman parte a lo largo de ésta. La sección tres muestra el cálculo del Índice de Concentración Herfindal-Hirschmann y nos indica una cadena de comercialización 
altamente concentrada en la importación de petróleo y sus derivados, así como en la venta de combustibles al consumidor final. La sección cuatro introduce al lector al concepto de transmisión asimétrica de precios, así como sus posibles causas. La quinta sección describe la serie de datos a utilizar, el modelo y los resultados de éste. La sección seis presenta las conclusiones del estudio.

\section{Cadena de producción y distribución de la gasolina}

En Nicaragua, el proceso de importación y comercialización del petróleo y sus derivados involucra a diferentes actores. El país importa tanto petróleo crudo como productos ya terminados que luego son comercializados por medio de las diferentes cadenas de estaciones de servicio que operan a nivel nacional. El siguiente esquema resume por fases y actores el proceso de comercialización del crudo y productos refinados. A grandes rasgos podemos identificar tres fases: importación y almacenamiento (de crudo y productos ya procesados), refinación, y distribución y venta al consumidor final. Paralelamente, participan de estos procesos la empresa estatal Petróleos de Nicaragua (PETRONIC), la Esso Standard Oil S.A. Limitada (ESSO) (refinería y cadena de distribución), Chevron Caribbean Inc. (TEXACO), Shell de Centroamérica (SHELL) y Distribuidora Nicaragüense de Petróleos (DNP), que operan las cadenas de estaciones de servicio. A continuación desarrollamos más en detalle las relaciones entre las diferentes empresas a lo largo de la estructura de distribución y comercialización.

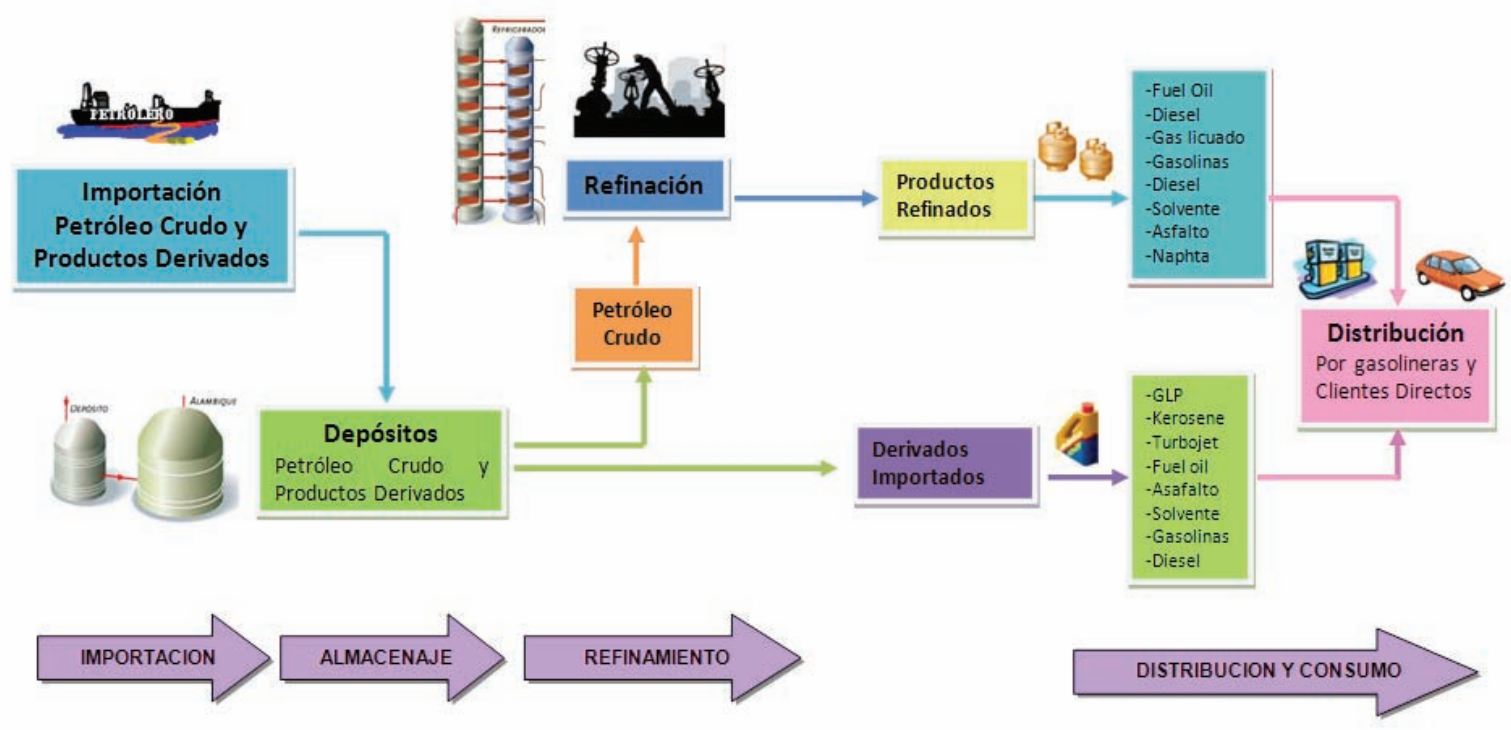

Ilustración 1. Cadena de comercialización de petróleo e hidrocarburos en Nicaragua 


\subsection{Importación}

Durante el año 2007 Nicaragua importó un total de 11,099.6 miles de barriles (en adelante, $\mathrm{mb}$ ) de petróleo y derivados, que conjuntamente sumaron una factura petrolera de un poco más de 783.1 millones de dólares. Del total importado, 5,744.8 mb fueron importaciones de petróleo crudo ${ }^{2}(51.81 \%)$ y $5,552.4 \mathrm{mb}$ fueron importaciones de derivados (48.19\%), entre los que se incluye Avgas, GLP, gasolinas (regular y súper) diesel, fuel oil, asfalto, solvente, coke y Naphta ${ }^{3}$.

Nicaragua importó esos productos desde catorce países ${ }^{4}$, sin embargo, las importaciones de crudo provinieron únicamente de cuatro países: México (32.4\%), Venezuela (19.6\%), Ecuador (19.2\%) y Estados Unidos (15.1\%). Del proceso de importación participan once empresas, de las cuales ESSO concentra el 64.26\% del total de las importaciones de crudo y sus derivados, seguida por DNP (12.47\%) y PETRONIC (5.18\%), cuyas importaciones se limitan a productos terminados.

Cuadro 1. Importaciones petroleras por producto y empresa (mb) año 2007

\begin{tabular}{|c|c|c|c|c|c|c|c|c|c|c|c|c|c|}
\hline Empresas & Crudo & Avgas & GLP & Regular & Súper & Diesel & $\begin{array}{c}\text { Fuel } \\
\text { Oil }\end{array}$ & Asfalto & Solvente & Coke & Naphta & TOTAL & $\%$ \\
\hline CEMEX Nicaragua, S.A. & & & & & & & & & & 641,30 & & 641,30 & 5,78 \\
\hline $\begin{array}{l}\text { Distribuidora } \\
\text { Nicaragüense de Petróleo, } \\
\text { S.A. (DNP) }\end{array}$ & & & & & 382,50 & 836,50 & 163,50 & & & & & $1.382,50$ & 12,47 \\
\hline $\begin{array}{l}\text { Empresa Energética de } \\
\text { Corinto (EEC) }\end{array}$ & & & & & & & 728,20 & & & & & 728,20 & 6,57 \\
\hline $\begin{array}{l}\text { Empresa Nicaragüense del } \\
\text { Petróleo, S.A. (PETRONIC) }\end{array}$ & & & & & 31,10 & 523,70 & 19,50 & & & & & 574,30 & 5,18 \\
\hline $\begin{array}{l}\text { Esso Standard Oil, S.A. } \\
\text { Ltd. (ESSO) }\end{array}$ & $5.744,80$ & & & 65,30 & 486,30 & 783,40 & & & 1,20 & & 44,80 & $7.125,80$ & 64,26 \\
\hline $\begin{array}{l}\text { Hidrocarburos de } \\
\text { Nicaragua, S.A. (HINISA) }\end{array}$ & & 3,40 & & & & & & & & & & 3,40 & 0,03 \\
\hline $\begin{array}{l}\text { Puerto Cabezas Power } \\
\text { (PCP) }\end{array}$ & & & & & & & 32,30 & & & & & 32,30 & 0,29 \\
\hline $\begin{array}{l}\text { Shell de Nicaragua S.A. } \\
\text { (SHELL) }\end{array}$ & & & & & & & & 54,80 & & & & 54,80 & \\
\hline TRANSMERQUIM & & & & & & & & & 4,00 & & & 4,00 & \\
\hline $\begin{array}{l}\text { Tropigas de Nicaragua, } \\
\text { S.A. }\end{array}$ & & & 424,80 & & & & & & & & & 424,80 & 3,83 \\
\hline $\begin{array}{l}\text { Zeta Gas de Nicaragua, } \\
\text { S.A. }\end{array}$ & & & 116,80 & & & & & & & & & 116,80 & 1,05 \\
\hline Otros & & 0,30 & & & & & & & & & & 0,30 & \\
\hline Total & $5.744,80$ & 3,40 & 541,60 & 65,30 & 899,90 & $2.143,60$ & 943,50 & & & 641,30 & 44,80 & $11.088,20$ & 99,47 \\
\hline $\begin{array}{l}\text { Participación \% por } \\
\text { producto importado }\end{array}$ & 51,81 & 0,03 & 4,88 & 0,59 & 8,12 & 19,33 & 8,51 & & & 5,78 & 0,40 & 99,46 & \\
\hline
\end{tabular}

Fuente: Estadísticas de los Hidrocarburos, 2007. Ministerio de Energía y Minas. 
Como el lector habrá podido notar en el cuadro 1, Nicaragua importó productos refinados diversos: Avgas, GLP, gasolinas, diesel, fuel oil, asfalto, solvente, coke y naphta, por un monto de 5,343.4 mb, dentro de los cuales se incluyen $965.2 \mathrm{mb}$ de gasolinas y 2,143.6 mb de diesel. Todo lo anterior a pesar de que el país cuenta con una refinería para obtener dichos productos a partir del refinado del crudo. La explicación a tal situación se encuentra en la capacidad limitada (y obsoleta) de la refinería ESSO y la alta demanda de hidrocarburos en el país. La capacidad de refinamiento de la refinería ronda los 20 mil barriles al día, algo menos de 7.3 millones de barriles al año. Considerando el consumo anual de hidrocarburos de 2007 en Nicaragua -de un total de 10,350.6 mb-, resulta evidente la necesidad de importar para suplir la demanda insatisfecha por la refinería ${ }^{5}$.

En el caso específico de las gasolinas y el diesel -que constituye el tema central de nuestro estudio- participan en el proceso de importación de estos derivados la ESSO, DNP y PETRONIC, únicas empresa en Nicaragua con instalaciones de almacenamiento de dichos productos. Conjuntamente estas empresas importaron un total 3,108.8 mb entre gasolinas y diesel. La ESSO importó en 2007 un total de $551.6 \mathrm{mb}$ de gasolinas y $783.4 \mathrm{mb}$ de diesel. Adicionalmente, la DNP también importó $382.5 \mathrm{mb}$ de gasolina súper y $836.5 \mathrm{mb}$ de diesel. Por su parte, PETRONIC realizó importaciones de gasolina súper y diesel por el orden de $31.1 \mathrm{mb}$ y $523.7 \mathrm{mb}$ respectivamente. En total, Nicaragua importó en 2007, a través de estas empresas, $65.3 \mathrm{mb}$ de gasolina regular, $899.9 \mathrm{mb}$ de gasolina súper y 2,143.6 mb de diesel.

\subsection{Refinación}

El petróleo importado es recibido y almacenado en la terminal de la ESSO en Puerto Sandino, donde cuenta con depósitos para almacenar hasta $648.3 \mathrm{mb}$ de crudo $^{6}$. Esta materia prima es luego trasladada hasta la única refinería en Nicaragua -ubicada en las cercanías de la cuesta El Plomo-, operada por la transnacional ESSO, para ser refinada. En dicha planta fueron refinados un total de 5,765.6 mb de crudo para obtener diversos derivados, principalmente fuel oil, diesel y gasolinas. La siguiente ilustración resume los volúmenes obtenidos producto del refinado del petróleo durante el año 2007. 


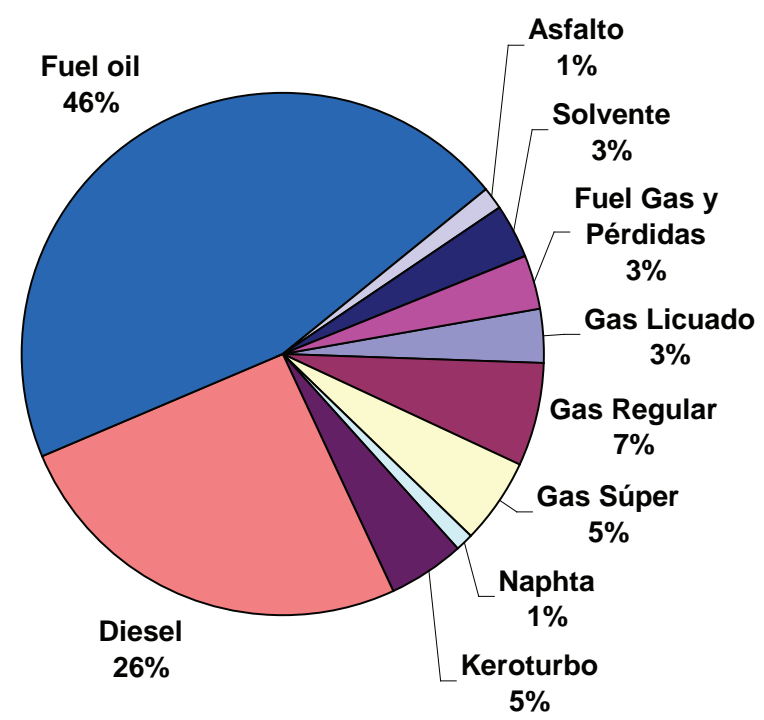

Ilustración 2. Producción de derivados del petróleo en refinería ESSO Managua, 2007 Fuente: Estadísticas de los Hidrocarburos, 2007. Ministerio de Energía y Minas.

Adicionalmente, del proceso de refinado se puede obtener los productos GLP, kerosén, turbo jet, fuel oil, asfalto y solvente. Todo lo anterior es posible por la conversión primaria mediante el proceso conocido como Hidroskimming (ver el proceso de refinamiento en el anexo 1).

\subsection{Distribución y venta?}

En la etapa de distribución y venta de los productos derivados del petróleo intervienen tanto el stock de productos terminados importados como el stock de productos refinados procesados por la ESSO en el país. La siguiente ilustración resume la estructura de ventas por derivados del petróleo en Nicaragua durante el año 2007, que totalizó 8,977.4 mb. 


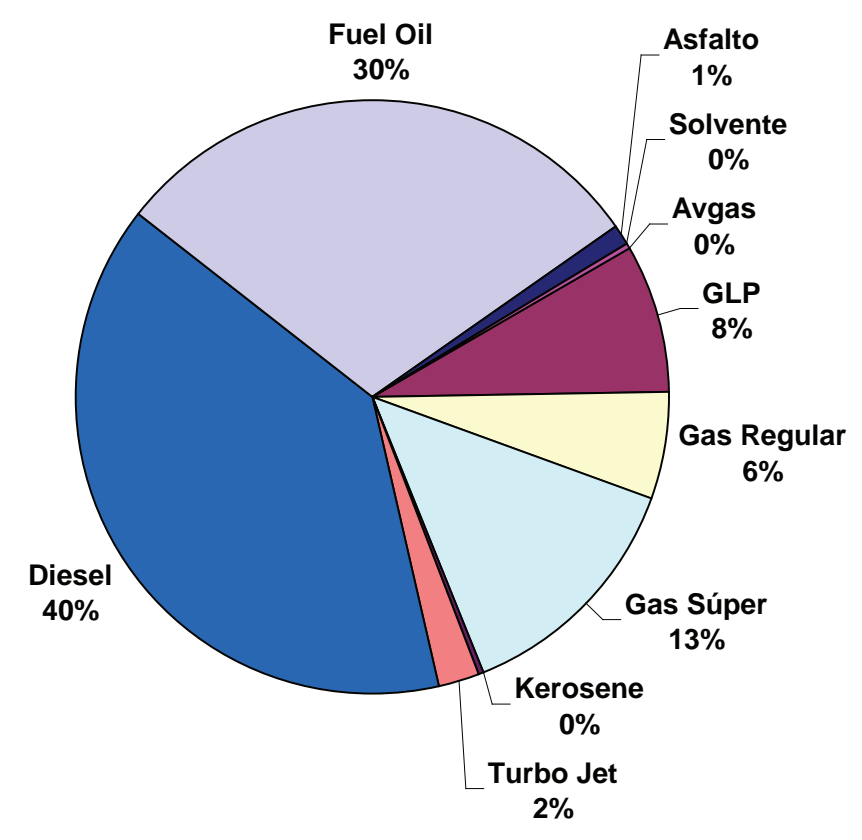

Ilustración 3. Venta de los derivados del petróleo, año 2007

Fuente: Estadísticas de los Hidrocarburos, 2007. Ministerio de Energía y Minas.

En lo que concierne específicamente a la distribución de las gasolinas y el diesel, toman parte SHELL, PETRONIC, ESSO, DNP y TEXACO, vendiendo estos productos a través de su red de estaciones de servicio $^{8}$ y por medio de provisión directa a otros clientes, como lo resume el cuadro 2. De los datos se desprende que la ESSO es la principal distribuidora de dichos productos con una cuota de mercado de $27 \%$, seguida por TEXACO, DNP y SHELL con una igual cuantía de mercado (21.4\%) y por ultimo PETRONIC, con 8.78\% del mercado. Para todas las cadenas el producto de mayor venta es el diesel, concentrando el $67 \%$ de las ventas. Vale aclarar que tanto la empresa SHELL como la TEXACO no realizan importaciones de combustibles y dependen directamente de la ESSO para la adquisición de gasolinas y diesel. Por otro lado, a pesar de que PETRONIC importa productos terminados (gasolina súper y diesel) como muestra el cuadro 1, dicha empresa participa de forma muy limitada en el proceso de comercialización de los mismos, con apenas algo menos del 9\% de las ventas totales. Dado que esta empresa no cuenta con una cadena de estaciones para la venta directa a consumidores (las estaciones PETRONIC pertenecen a la Corporación Glencore bajo la empresa DNP), la misma realiza casi la totalidad de sus ventas (95.85\%) a clientes directos. A continuación describimos la situación por cada canal de distribución. 
Cuadro 2. Venta de los derivados del petróleo por empresa (mb) año 2007

\begin{tabular}{|c|c|c|c|c|c|c|c|c|c|}
\hline Empresa & $\begin{array}{c}\text { Canal de } \\
\text { venta }\end{array}$ & $\begin{array}{c}\text { Gasolina } \\
\text { regular }\end{array}$ & $\%$ & $\begin{array}{l}\text { Gasolina } \\
\text { súper }\end{array}$ & $\%$ & Diesel & $\%$ & $\begin{array}{c}\text { TOTAL } \\
\text { ventas } \\
\text { por canal }\end{array}$ & $\begin{array}{c}\% \text { Ventas } \\
\text { por } \\
\text { canal }\end{array}$ \\
\hline TEXACO & Clientes directos & 0,10 & 0,05 & 1,70 & 0,71 & 105,60 & 15,51 & 107,40 & 9,60 \\
\hline 21,41 & Estaciones servicio & 196,20 & 99,95 & 239,40 & 99,29 & 575,20 & 84,49 & $1.010,80$ & 90,40 \\
\hline \multicolumn{2}{|l|}{ TOTAL } & \multicolumn{2}{|l|}{196,30} & \multicolumn{2}{|l|}{241,10} & \multicolumn{2}{|l|}{680,80} & \multicolumn{2}{|l|}{$1.118,20$} \\
\hline DNP & Clientes directos & 0,00 & & 34,10 & 9,43 & 486,50 & 64,57 & 520,60 & 46,68 \\
\hline 21,36 & Estaciones servicio & 0,00 & & 327,70 & 90,57 & 266,90 & 35,43 & 594,60 & 53,32 \\
\hline \multicolumn{2}{|l|}{ TOTAL } & \multicolumn{2}{|l|}{0,00} & \multicolumn{2}{|l|}{361,80} & \multicolumn{2}{|l|}{753,40} & \multicolumn{2}{|l|}{$1.115,20$} \\
\hline PETRONIC & Clientes directos & 0,00 & & 22,30 & 80,51 & 417,10 & 96,84 & 439,40 & 95,86 \\
\hline 8,78 & Estaciones servicio & 0,00 & & 5,40 & 19,49 & 13,60 & 3,16 & 19,00 & 4,14 \\
\hline \multicolumn{2}{|l|}{ TOTAL } & \multicolumn{2}{|l|}{0,00} & \multicolumn{2}{|l|}{27,70} & \multicolumn{2}{|l|}{430,70} & \multicolumn{2}{|l|}{458,40} \\
\hline ESSO & Clientes directos & 23,60 & 14,16 & 7,50 & 2,67 & 448,50 & 46,58 & 479,60 & 34,00 \\
\hline 27,01 & Estaciones servicio & 143,10 & 85,84 & 273,40 & 97,33 & 514,40 & 53,42 & 930,90 & 66,00 \\
\hline \multicolumn{2}{|l|}{ TOTAL } & \multicolumn{2}{|l|}{166,70} & \multicolumn{2}{|l|}{280,90} & \multicolumn{2}{|l|}{962,90} & \multicolumn{2}{|l|}{$1.410,50$} \\
\hline SHELL & Clientes directos & 13,80 & 8,00 & 10,60 & 3,94 & 86,60 & 12,77 & 111,00 & 9,92 \\
\hline 21,44 & Estaciones servicio & 158,80 & 92,00 & 258,10 & 96,06 & 591,40 & 87,23 & $1.008,30$ & 90,08 \\
\hline \multicolumn{2}{|l|}{ TOTAL } & \multicolumn{2}{|l|}{172,60} & \multicolumn{2}{|l|}{268,70} & \multicolumn{2}{|l|}{678,00} & \multicolumn{2}{|l|}{$1.119,30$} \\
\hline \multirow[t]{3}{*}{$\begin{array}{l}\text { TOTAL } \\
\text { VENTAS }\end{array}$} & & 535,60 & & $1.180,20$ & & $3.505,80$ & & $5.221,60$ & \\
\hline & Clientes directos & 37,50 & 0,07 & 76,20 & 0,06 & $1.544,30$ & 0,44 & $1.658,00$ & 0,32 \\
\hline & Estaciones servicio & 498,10 & 0,93 & $1.104,00$ & 0,94 & $1.961,50$ & 0,56 & $3.563,60$ & 0,68 \\
\hline
\end{tabular}

Fuente: Estadísticas de los Hidrocarburos, 2007. Ministerio de Energía y Minas.

La DNP es una empresa que forma parte de Glencore Internacional y que ostenta una concesión de diez años (se vence en 2009) para la operación y explotación de las estaciones de servicio bajo la marca/nombre PETRONIC y los depósitos de almacenamiento en Corinto ${ }^{9}$. Durante el 2007 DNP vendió gasolinas y diesel por el orden de 1,115.2 mb a través de estaciones de servicio y ventas directas a clientes. La marca DNP no vende gasolina regular, sino gasolinas con o sin aditivos que representan el 32\% de sus ventas canalizadas en su mayoría (91\%) por medio de estaciones de servicio. Por el contrario, las principales ventas de diesel (65\%) se realizan a clientes directos.

Por otro lado, la empresa estatal PETRONIC importó $31.1 \mathrm{mb}$ de gasolina súper y $523.7 \mathrm{mb}$ de diesel que almacenó en los tanques arrendados a la ESSO en Corinto y Piedras Blancas ${ }^{10}$. Dado que PETRONIC carece de la infraestructura necesaria (estaciones de servicio) para la comercialización de combustible, esta empresa canalizó el 96\% de sus ventas directamente 
a clientes, incluidas otras cadenas distribuidoras de hidrocarburos ${ }^{11}$. Entre sus ventas el 94\% fueron de diesel, destinado a alimentar a las Plantas Generadoras Hugo Chávez (Las Brisas y Los Brasiles) y abastecer al sector del transporte urbano de Managua con producto subsidiado, bajo el acuerdo de cooperación entre los gobiernos de Venezuela y Nicaragua llevado a cabo por medio de la Alternativa Bolivariana para las Américas (ALBA).

La empresa ESSO, que concentra el 64\% de las importaciones petroleras de Nicaragua y opera la única refinería en el país, concentra el 27\% de las ventas de diesel y gasolinas. Durante el año 2007, el total de productos refinados importados (gasolinas y diesel) alcanzó la cifra de 1,335 mb, de los cuales $486.3 \mathrm{mb}$ fueron de gasolina súper, $65.3 \mathrm{mb}$ de gasolina regular $^{12}$ y $783.4 \mathrm{mb}$ de diesel. Adicionalmente, la ESSO proveyó, por medio del refinado de petróleo, $378.6 \mathrm{mb}$ de gasolina regular, $298.3 \mathrm{mb}$ de gasolina súper y 1,477.5 mb de diesel. De estos, la empresa vendió $166.7 \mathrm{mb}$ de gasolina regular, $280.9 \mathrm{mb}$ de gasolina súper y 962.9 mb de diesel. Similar a la DNP, la ESSO canalizó el 93\% de sus ventas de gasolinas por medio de estaciones de servicio y el $47 \%$ de sus ventas de diesel por medio de ventas a clientes directos.

En el caso de SHELL y TEXACO, ambas empresas dependen directamente de la ESSO para el suministro de hidrocarburos (gasolinas y diesel) para su posterior venta, dado que ninguna de estas empresas participa en el proceso de importación de productos terminados. SHELL y TEXACO compran sus combustibles a la ESSO con la única diferencia de que a cada producto es agregado el aditivo propio de cada marca de combustible. En el caso de la empresa SHELL, para el año 2007 vendió 1,119.3 mb de productos terminados divididos en $172.6 \mathrm{mb}$ de gasolina regular, $268.7 \mathrm{mb}$ de gasolina súper y $678 \mathrm{mb}$ de diesel. De manera similar, TEXACO vendió en concepto de gasolinas y diesel durante el año 2007 un total de 1,118.2 mb, divididos en $196.3 \mathrm{mb}$ de gasolina regular, $242.1 \mathrm{mb}$ de gasolina súper y 680.8 mb de diesel. A diferencia de las otras empresas distribuidoras, tanto la SHELL como la TEXACO canalizaron el 90\% de sus ventas por medio de estaciones de servicio. El cuadro 2 resume las ventas de combustibles por empresa -tanto en estaciones como a clientes directos $^{13}$ - durante el año 2007.

\subsection{Concentración en la cadena de comercialización}

Para concluir nuestra descripción de la cadena de comercialización de hidrocarburos -en especial gasolinas y diesel- en Nicaragua, evaluamos el nivel de concentración de la industria en la fase de distribución y venta de dichos productos. Para ello calculamos el Índice de Concentración Herfindal y Hirschmann, que pondera de manera adecuada el poder de mercado de los participantes. Este índice es calculado como la suma de los cuadrados de las cuotas de mercado de cada una de las empresas que operan en el mercado ${ }^{14}$. Dentro de los valores que puede tomar el índice, existen tres categorías que determinan la posición en la que se encuentra el mercado:

- Alta concentración ( $\mathrm{IHH}>0.18)$ : Cuando uno de los participantes percibe el total del valor del mercado y los demás nada. En este caso, existe un reparto no equitativo o concentrado.

- Concentración moderada $(0.18>\mathrm{IHH}>0.10)$ : Cuando es un mercado moderadamente 
concentrado.

- No concentración (0.10> IHH): Cuando el valor del mercado está repartido equitativamente entre todos los participantes.

$\mathrm{Al}$ aplicar esta metodología para el cálculo del índice sobre la base de la cuota de mercado (ventas anuales por medio de estaciones y a clientes directos) de cada una de las cadenas/ marcas de combustibles, incluida PETRONIC, obtenemos un índice de concentración alto para la industria en la fase de distribución y venta de gasolinas (0.2439) y diesel (0.2118), tal y como lo muestra el cuadro 3. Si excluimos del cálculo a PETRONIC, cuya participación en las ventas totales llega a menos del 9\% por falta de estaciones de servicio para despacho directo al consumidor, los valores del índice aumentan a 0.2517 para las gasolinas y 0.2611 para el diesel, mostrando un mayor nivel de concentración de la industria en la fase de distribución y ventas.

Cuadro 3. Índice Herfindal-Hirschmann en base a ventas de gasolinas y diesel año 2007

\begin{tabular}{|c|c|c|c|c|c|c|}
\hline Empresa & Gasolinas & $\%$ & $(\%)^{2}$ & Diesel & $\%$ & $(\%)^{2}$ \\
\hline $\begin{array}{l}\text { Chevron Caribbean Inc. } \\
\text { (TEXACO) }\end{array}$ & 437,40 & $25,49 \%$ & 0,0650 & 680,80 & $19,42 \%$ & 0,0377 \\
\hline PETRONIC (DNP) & 361,70 & $21,08 \%$ & 0,0444 & 753,40 & $21,49 \%$ & 0,0462 \\
\hline $\begin{array}{l}\text { Empresa Nicaragüense del } \\
\text { Petróleo (PETRONIC) }\end{array}$ & 27,70 & $1,61 \%$ & 0,0003 & 430,70 & $12,29 \%$ & 0,0151 \\
\hline Esso Standard Oil, S.A (ESSO) & 447,60 & $26,09 \%$ & 0,0681 & 962,90 & $27,47 \%$ & 0,0754 \\
\hline $\begin{array}{l}\text { Shell de Nicaragua, S.A. } \\
\text { (SHELL) }\end{array}$ & 441,40 & $25,73 \%$ & 0,0662 & 678,00 & $19,34 \%$ & 0,0374 \\
\hline TOTAL & $1.715,80$ & $100,00 \%$ & & $3.505,80$ & $100,00 \%$ & \\
\hline Índice Herfindal-Hirschmann & & & 0,2439 & & & 0,2118 \\
\hline
\end{tabular}

Fuente: Elaboración propia en base a Estadísticas de los Hidrocarburos, 2007. Ministerio de Energía y Minas.

Por otro lado, queremos subrayar que a pesar de la equitativa distribución de cuotas de mercado, la cadena de comercialización refleja que el gran suplidor del mercado nacional es la ESSO ya que tanto la TEXACO como la SHELL realizan compras a esta última. Dichas empresas no solamente dependen de la ESSO para la compra y posterior distribución y venta de combustibles, sino que también comparten la estructura de costos de elaboración de dichos combustibles. En términos del precio final al consumidor, una gran proporción del mismo viene determinado por precio de compra al cual adquieren ambas empresas los combustibles de parte de la ESSO. Las diferencias en el precio final al consumidor se deben a los juegos en los márgenes de comercialización que cada empresa puede asignar libremente. 
Así concluimos nuestra exposición de la cadena de hidrocarburos en Nicaragua. En las dos secciones siguientes introducimos el fenómeno de transmisión asimétrica de precios entre los precios de referencia y los precios finales al consumidor de los hidrocarburos, así como las razones que dan lugar al mismo. Adicionalmente presentamos el modelo matemático para identificar y cuantificar la presencia o ausencia de asimetría de precios, y los resultados obtenidos del mismo.

\section{Asimetría de precios}

\subsection{Definición de movimientos asimétricos de los combustibles}

Esta transmisión asimétrica de precios se refiere a un proceso en el cual los movimientos del precio de la gasolina "no responden simétricamente a cambios en los precios en las primeras etapas de la cadena de valor"(Karrenbrock, 1991:19). Es decir, cuando un alza en los precios de la materia prima (petróleo) afecta de forma más rápida y concentrada al precio del producto final (gasolinas/diesel) que una baja. Bacon explica este proceso de una forma más clara: "Cuando las compañías enfrentan incrementos en los costos elevan rápidamente los precios, pero cuando enfrentan decrementos en los costos reducen lentamente los precios, permitiendo así niveles temporales de altos rendimientos" (Bacon, 1991:211).

En la teoría existente se pueden definir tres tipos de asimetría: velocidad de ajuste, magnitud, y una combinación de ambas. La velocidad de ajuste se refiere al tiempo en el que los precios de los combustibles responden a cambios en los precios del petróleo. O sea, existe asimetría en la velocidad de ajuste si un incremento en el precio del petróleo se transmite en menor tiempo al precio de la gasolina que un decremento del mismo. La magnitud se refiere a la cantidad del cambio en el precio del petróleo que es transmitida al precio de los combustibles. Por ejemplo, existe asimetría en la magnitud de la transmisión si un incremento de C\$10 en el precio del petróleo lleva a un incremento de C\$8 en el precio de la gasolina, mientras que un descenso de C\$10 en el precio del petróleo conlleva a un descenso de C\$5 en el precio de la gasolina. El tercer tipo de asimetría es una combinación de la velocidad en la cual se ajusta el precio con la magnitud con que se ajusta.

Existe simetría en la velocidad de ajuste y en la magnitud si el precio de la gasolina se ajusta en el mismo tiempo y en la misma cantidad a incrementos y a decrementos en el precio del petróleo. Aún así puede existir asimetría si el patrón de ajuste tanto para la velocidad como para la magnitud difiere dependiendo de si los precios del petróleo suben o bajan. Tomaremos como ejemplo una situación en la que el precio del petróleo tiene un incremento y un decremento de $\mathrm{C} \$ 10$ y los precios de la gasolina aumentan y descienden $\mathrm{C} \$ 8$ en un período de dos meses conjuntamente. Existe simetría tanto en velocidad de ajuste como en magnitud. Sin embargo, puede haber asimetría si el patrón de ajuste es el siguiente: ante el incremento de C\$10 en el precio del petróleo el precio de la gasolina aumenta C\$6 en el primer mes y C\$2 en el segundo mes; por el contrario, ante un descenso de C\$10 del precio del petróleo el precio de la gasolina desciende C $\$ 2$ en el primer mes y C\$6 en el segundo mes. En este caso, el patrón de ajuste combinado de la velocidad y la magnitud es asimétrico. 


\subsection{Por qué surge la asimetría}

Las causas del comportamiento asimétrico de los precios son varias, las más importantes son: poder de mercado, costos de búsqueda y costos de inventarios.

\subsubsection{Poder de mercado}

Kinnucan y Forker vinculan la concentración de la industria como un factor que explica la transmisión asimétrica de precios en los mercados: "producto de la concentración de la industria...., es comúnmente acertado que los intermediarios utilizan el poder de mercado para utilizar estrategias de precios que resultan en una rápida y completa transmisión de precios cuando el costo incrementa y una transmisión menos que completa cuando los costos se reducen" (Kinnucan y Forker, 1987:285). Por ejemplo, consideremos una industria con unas cuantas firmas dominantes que entablan una colusión tácita para mantener un margen de beneficio alto. En este contexto, la reputación resulta de suma importancia para mantener el acuerdo de colusión. Si las empresas de distribución (estaciones de servicio) cuentan con información incompleta acerca de los precios de compra de sus competidoras, cada una se mostrará más dispuesta a subir que a bajar sus precios de venta. Cuando los precios río arriba en la cadena de comercialización aumentan, cada firma responderá rápidamente con un aumento de sus precios para mostrar a sus competidores que sigue cumpliendo con el acuerdo al no reducir su margen. Por el contrario, cuando los precios río arriba sufren un decremento, cada firma responde lentamente en la reducción de sus precios para no enviar la señal equivocada a sus competidores de que quieren romper el acuerdo. Esta explicación puede ser aplicada a cada cambio de precio río arriba y su consecuente efecto en los precios río abajo a lo largo de toda la cadena de comercialización de los combustibles (Balke et al., 1998:4).

Dado que tanto la refinería como los minoristas (SHELL, ESSO, TEXACO, PETRONIC) juegan un rol en la determinación de los precios finales al consumidor de los combustibles, una posible transmisión asimétrica puede ocurrir entre cualquiera de estos agentes. En nuestra descripción de la cadena de comercialización establecimos como mayor suplidor de combustibles a la empresa ESSO, lo que elimina la información incompleta de precios de compra ${ }^{15}$ para las empresas ESSO, SHELL y TEXACO. Sin embargo, esto no implica que las estaciones de servicio puedan jugar con el margen de ganancia al detallista y puedan establecer estos tipos de arreglos tácitos con los precios finales al consumidor.

\subsubsection{Costos de búsqueda}

En el mercado detallista de los combustibles, los costos de búsqueda de los consumidores pueden llevar a una situación temporal de poder de mercado de las estaciones de servicio y a una respuesta asimétrica en el cambio de los precios de los combustibles ante cambios en los precios río arriba (Borenstein et al.,1997:328-9). En el mercado, cada estación de servicio ostenta un monopolio territorial, limitado por los costos de búsqueda de los consumidores. Los altos costos de búsqueda de mejores precios por parte de los consumidores le otorgan a las gasolineras ese poder monopólico, ya que los costos de una búsqueda intensa probablemente sean más altos para la mayoría de los consumidores que las ganancias correspondientes de 
encontrar un precio más bajo. Por lo tanto, muchos no realizan la búsqueda. Bajo estas circunstancias, cuando los precios suben río arriba, cada estación de servicio reacciona elevando el precio de los combustibles para mantener su margen de ganancia. En tanto, cuando los precios río arriba bajan, la cautividad temporal de clientes que tiene la estación de servicio le permite bajar gradualmente el precio y así aumentar su margen de ganancia temporalmente (Soruco, 2004:6-7). Este poder de mercado temporal de las estaciones de servicio reduce la velocidad y magnitud de transmisión de los cambios de precios río arriba hacia los precios de los combustibles. Sólo hasta que los consumidores han asumido los costos de búsqueda (en tiempo y recursos) por mejores precios, el mercado alcanza reducir sus precios a niveles competitivos (Brown \& Yucel, 2000:26).

\subsubsection{Costos de ajuste de mercado}

Otra explicación al rezago de respuesta de los precios de los combustibles ante cambios en el precio del petróleo son los costos de manejo de inventario. Esto es porque si existen costos de mantener el nivel adecuado de inventarios, el ajuste al nivel de precios no será inmediato. Esto se ve en una situación en la que "si el costo de operación aumenta rápidamente cuando los inventarios están por debajo de los niveles normales de operación, una reducción de la oferta puede conllevar a que la firma eleve sus precios agresivamente con el fin de prevenir la pérdida en inventarios. Si un aumento en el nivel de inventarios mas allá del nivel normal tiene bajo impacto en costos, la firma actuará de forma menos agresiva al momento de bajar sus precios cuando experimenta un aumento de la oferta" (Balke et al., 1998:4). La asimetría proveniente de cambios en los inventarios también puede surgir de los sistemas contables de inventarios que usan las empresas distribuidoras. Bajo un sistema UEPS (último en entrar, primero en salir) las empresas ajustan inmediatamente los precios de los combustibles ante cambios en los precios del petróleo. Mientras que bajo un sistema de inventarios PEPS (primero en entrar, primero en salir) las empresas no ajustarán el precio de los combustibles ante cambios del precio del petróleo sin antes haber vendido sus primeros inventarios. Así, bajo un sistema PEPS, las estaciones de servicio venden sus productos a un precio más caro hasta que sus productos comprados a precios más elevados se agoten.

\section{Investigación empírica}

\subsection{Data (serie de tiempo)}

Para establecer y cuantificar la presencia de asimetría entre las variaciones de los precios internacionales y nacionales de los hidrocarburos, optamos por correr un modelo para la gasolina súper y otro para el diesel ${ }^{16}$ siguiendo la metodología de Jeffrey Karrenbrock (1991) que en breve describiremos. En cada modelo se utilizó la serie de tiempo del INE que registra los precios semanales nacionales y los precios internacionales diarios de los combustibles. La serie de tiempo utilizada en ambos modelos consta de 144 observaciones semanales partiendo desde la semana del 2 de enero de 2006 hasta la semana del 27 de octubre de 2008 (ver anexo IV). 
Es importante aclarar que las cadenas distribuidoras de hidrocarburos en Nicaragua no utilizan el precio internacional del petróleo WTI para el cálculo de los precios de los combustibles en el mercado nicaragüense. A diferencia de lo que muchos creen, las compañías -en especial la ESSO como empresa líder que sugiere los precios de referencia nacionalutilizan los precios internacionales de los hidrocarburos de la Costa del Golfo de los Estados Unidos como referencia para sus cálculos. En el caso de esta serie de tiempo, fue necesario efectuar un ajuste y promediar los precios diarios para obtener un solo valor representativo de la semana y en correspondencia con la serie de precios domésticos semanales. A su vez, para expresar ambas series en las mismas unidades monetarias y unidades de medida, dos transformaciones adicionales fueron realizadas. Por un lado, la serie de precios nacionales expresada en córdobas por litro fue transformada a dólares por litro, dividiendo el precio semanal por el tipo de cambio oficial del día en que fue publicada la lista de precios por el INE. Por otro lado, los precios internacionales expresados en dólares por galón fueron transformados a dólares por litros, dividiendo cada unidad por 3.785.

\subsection{Especificación del modelo}

Para comprobar la existencia o la ausencia de asimetrías en la transmisión de los precios de los combustibles en el mercado nicaragüense elaboramos un modelo que mide las relaciones estadísticas entre las variaciones semanales de los precios internacionales de la gasolina súper y diesel con las variaciones semanales de los precios de dichos productos en Nicaragua. Siguiendo la metodología utilizada por Jeffrey Karrenbrock (1991), el modelo especifica que el precio nacional semanal de cada combustible (gasolina súper o diesel) está en función del precio internacional promedio semanal del combustible en cuestión. Se puede definir como:

$$
P N_{\mathrm{i}, \mathrm{t}}=\alpha+\beta P I_{\mathrm{i}, \mathrm{t}}+u_{t}
$$

Donde: $\boldsymbol{P N}_{i, t}$ es el precio nacional del combustible

$$
\begin{aligned}
& P \boldsymbol{I}_{i, t} \text { es el precio internacional del combustible } \\
& \mathbf{a} \text { es el coeficiente del intercepto } \\
& \boldsymbol{u}_{\boldsymbol{t}} \text { es el error con ruido blanco }
\end{aligned}
$$

Para comprobar cómo el efecto de un incremento en los precios internacionales es diferente al efecto que causa un decremento de los precios internacionales en los precios domésticos, se han dividido las variaciones de los precios en alzas (A) y bajas (B). Esto quiere decir que el ajuste del precio nacional en una semana específica es explicado por el cambio que experimentó el precio internacional en las semanas anteriores.

$$
\begin{aligned}
& { }_{\triangle} A P I_{i, t}=A P I_{i, t}-A P I_{i, t-1} \text { si, }\left(A P I_{i, t}-A P I_{i, t-1)}>0 \text { y } 0\right. \text { en otro caso }
\end{aligned}
$$

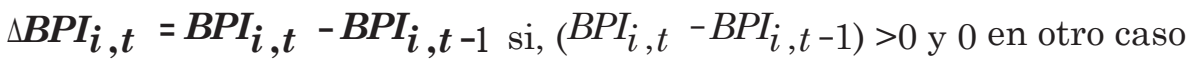


La prueba Dickey-Fuller realizada a las series nos permitió determinar que la serie de precios nacionales de la gasolina (PNG) súper posee raíz unitaria y que es estacionaria en primera diferencia I(1) (ver anexo II). Para corregir la no estacionariedad, la serie de tiempo de dicho producto se trabajó en primera diferencia. Esta diferenciación se distingue así:

$$
\Delta P N_{i, t}=P N_{i, t}-P N_{i, t-1}
$$

Una vez realizada la primera diferencia de la variable PNG y la diferencia entre alzas y bajas, la ecuación del modelo es representada de esta manera:

$$
\Delta P N=\alpha+\beta_{1} \Delta A P I_{t-j}+\sum_{2} \Delta \mathrm{BPI}+e_{t}
$$

Donde: $\triangle \boldsymbol{P N}$ es el operador de primera diferencia del precio nacional.

a es el coeficiente del intercepto.

$\triangle \boldsymbol{A P I}$ es un alza o incremento en el precio internacional.

$\triangle \boldsymbol{B P I}$ es una baja o decremento en el precio internacional.

$\boldsymbol{e}_{\boldsymbol{t}}$ es el error con ruido blanco.

Así, todos los APIt son positivos o cero y todos los BPIt son negativos o cero. Si el precio nacional responde simétricamente tanto a incrementos como a decrementos del precio internacional tendríamos que $B_{1=} B_{2}$.

Para medir la velocidad de ajuste y el patrón de ajuste, en el modelo se especificarán el número de rezagos en los cuales APIt y BPIt transmiten sus variaciones al precio nacional. Esta especificación se define como:

$$
\Delta P N_{t}=\beta_{0}+\Sigma \beta_{1} A P I_{t-i}+\Sigma \beta_{2} B P I_{t-i}
$$

Donde: p y q son el número de rezagos para los incrementos y decrementos en el precio internacional. ${ }^{17}$

Para medir si existe asimetría en magnitud se verificará así:

$$
\Sigma \beta_{1} A P I_{t-i}=\Sigma \beta_{2} B P I_{t-\mathrm{I}}
$$

Esto nos indicará si la transmisión de precios difiere o no en cantidad (magnitud) en dependencia de si se trata de un incremento o de un decremento en el precio internacional. Para medir la existencia o la ausencia de asimetría en la velocidad de ajuste -que consiste en establecer si el tiempo que toma en ajustarse el precio nacional de la gasolina es igual tanto para incrementos como para decrementos en el precio internacional de la gasolinase tratará de comprobar si el número de rezagos es igual tanto para las alzas como para las bajas.

$$
q=p
$$


Si el número de rezagos tanto para las alzas como para las bajas es igual, se rechazará la hipótesis nula de asimetría en velocidad de ajuste, de lo contrario se aceptará.

$$
H_{0}: r \neq s
$$

\subsection{Patrón de asimetría}

El patrón de asimetría se define como la presencia tanto de asimetrías en magnitud como en velocidad de ajuste. Esto nos indicará si la transmisión de precios difiere o no, en cantidad (magnitud) y en el número de rezagos, en dependencia de si se trata de un incremento o de un decremento en el precio internacional. Así, el patrón de ajuste se refiere al análisis en conjunto de los dos tipos iniciales de asimetría.

\section{Resultados del modelo}

\subsection{Modelo diesel}

En el modelo del diesel se encontró asimetría tanto en magnitud como en velocidad. Se encontró asimetría negativa en velocidad de ajuste debido a que el tiempo que toma en ajustarse el precio nacional del diesel no es el mismo para incrementos como para descensos en el precio internacional del diesel. El precio internacional se transmite de manera más rápida cuando desciende que cuando aumenta. Por lo que los rezagos de las alzas en el precio no son iguales a los rezagos de las bajas, esto se puede ver de la siguiente manera:

$$
A P I D_{t-3} \neq B P I D_{t-2}
$$

Las alzas en el precio nacional del diesel se ajustan en tres períodos, mientras que las bajas en el precio nacional del diesel se ajustan en dos períodos. Por lo tanto, se acepta la hipótesis nula de asimetría en velocidad de ajuste.

$$
H_{0}: r \neq s
$$

Se encontró asimetría en magnitud debido a que:

$$
\begin{aligned}
\Sigma \mathbf{a} 1 A P I D_{t-i} & \neq \Sigma \mathbf{a} \mathbf{2 B P I D} \\
1.1081 & \neq 1 . \mathrm{I}
\end{aligned}
$$

Es decir, cuando hay un incremento de $\$ 1$ por litro en el precio internacional del diesel, el precio nacional del diesel se ajusta de la siguiente manera: en la primera semana se incrementa el precio nacional en $\$ 0.4238$; en la segunda semana se vuelve a incrementar en $\$ 0.4582$; y en la tercera semana se incrementa en 0.2260 , sumando un total de $\$ \mathbf{1 . 1 0 8 1}$, es decir, $\$ 0.108$ por litro más de lo que se incrementa en el precio internacional. Por otro lado, cuando hay un decremento de $\$ 1$ por litro en el precio internacional, el precio nacional se ajusta de la siguiente manera: en la primera semana hay un decremento de $\$ 0.5746$ y en la segunda semana vuelve a haber otro decremento de $\$ 0.4269$, sumando un total de $\$ \mathbf{1 . 0 0 1 5}$, es decir, desciende en la misma cantidad que desciende el precio internacional. 


\subsection{Modelo gasolina súper}

En el modelo de la gasolina súper también se encontró asimetría en magnitud como en velocidad. Se encontró asimetría en velocidad de ajuste debido a que el tiempo que toma en ajustarse el precio nacional de la gasolina súper no es el mismo tanto para incrementos como para descensos en el precio internacional de la gasolina súper, por lo que los rezagos de las alzas en el precio no son iguales a los rezagos de las bajas, esto se puede ver de la siguiente manera:

$$
A P I G S_{t-4} \neq B P I G S_{t-2}
$$

Las alzas en el precio nacional de la gasolina súper se ajustan en cuatro períodos sin tomar en cuenta el período "t"; mientras que las bajas en el precio nacional de la gasolina súper se ajustan en tres periodos tomando en cuenta el período " $t$ ". Por lo tanto, se acepta la hipótesis nula de asimetría negativa en velocidad de ajuste. Este tipo de asimetría, negativa, es beneficiosa para el consumidor debido a que significa que el precio de las bajas se transmite más rápido que el precio de las alzas, al igual que en el caso del diesel.

$$
H_{0}: r \neq s
$$

Se encontró asimetría en magnitud debido a que:

$$
\begin{aligned}
\Sigma \mathbf{a} 1 A P I G S_{t-i} & \neq \Sigma \mathbf{a} 2 B P I G S_{t-\mathrm{I}} \\
1.23^{\prime} & \neq 0.91
\end{aligned}
$$

Es decir, cuando hay un incremento de $\$ 1$ por litro en el precio internacional de la gasolina súper, el precio nacional se ajusta de la siguiente manera: en la primera semana se incrementa en $\$ 0.2574$; en la segunda semana se vuelve a incrementar en $\$ 0.5347$; en la tercera semana se incrementa en $\$ 0.2545$; y en la cuarta semana se incrementa en $\$ 0.1522$, sumando un total de $\$ \mathbf{1 . 2 3}$, es decir, $\$ 0.23$ por litro más de lo que se incrementa en el precio internacional. Por otro lado, cuando hay un decremento de $\$ 1$ por litro en el precio internacional, el precio nacional de este producto se ajusta de la siguiente manera: en la misma semana hay un decremento en el precio nacional de $\$ 0.2774$; en la segunda semana vuelve a haber otro decremento de \$0.53111; y en la tercera semana hay otro decremento de $\$ 0.1119$, sumando un total de $\$ \mathbf{0 . 9 1}$, es decir, $\$ 0.09$ por litro menos de lo que desciende el precio internacional.

\section{Conclusiones}

Los hallazgos denuestrainvestigación describen una cadena decomercialización deproductos derivados del petróleo, específicamente de diesel y gasolinas, altamente concentrada. Nuestro cálculo del Índice de Concentración Herfindal-Hirschmann, excluyendo PETRONIC, arroja valores del índice excesivamente altos tanto para las gasolinas como para el diesel asociados a un reparto poco equitativo de la industria, en donde una empresa concentra un gran porcentaje del mercado en la fase de distribución y ventas. Los datos muestran que, una vez más, la empresa ESSO es la principal distribuidora de dichos productos, seguida por 
TEXACO, DNP y SHELL. Por el contrario, PETRONIC participa de forma muy limitada en el proceso de comercialización dada la falta de infraestructura (estaciones de servicio) para la venta a consumidores, por tanto concentra casi la totalidad de sus ventas (95.85\%) a clientes directos. Para todas las cadenas el producto de mayor venta es el diesel, concentrando el $67 \%$ de las ventas.

Por otro lado, la regresión de nuestro modelo para evaluar asimetrías en la transmisión desde los precios internacionales de los hidrocarburos hasta los precios domésticos de venta en Nicaragua, identificó la presencia de la misma tanto en magnitud como en velocidad para diesel y gasolina súper. En términos de la velocidad de ajuste de los precios, ambos productos exhiben asimetrías, dado que los períodos de ajuste difieren entre alzas y bajas de los precios. En presencia de alzas, los precios tienden a ajustarse más lento que en presencia de bajas en los precios internacionales. A simple vista, este comportamiento parece beneficiar a los consumidores dado que las bajas en los precios son transmitidas más rápidamente que las alzas en los mismos. Sin embargo, la magnitud en los ajustes de precios muestra otra historia totalmente diferente. Para ambos productos los incrementos en los precios internacionales conllevan a un aumento más que proporcional de los precios domésticos, siendo más significativo este ajuste para el diesel, lo que perjudica directamente a los consumidores y permite incrementar los beneficios de las empresas que comercializan el mismo. Por otro lado, las reducciones en los precios internacionales se traducen en reducciones de la misma magnitud para el diesel, no así para la gasolina, cuyo precio desciende menos que proporcionalmente al descenso experimentado en el precio internacional del mismo, una vez más permitiendo a las empresas incrementar sus beneficios.

Nuestra investigación apenas responde a la pregunta: ¿existe transmisión asimétrica entre los precios internacionales de los hidrocarburos y los precios domésticos de los mismos? Restan interrogantes en torno a los mecanismos de formación de precios utilizados por las empresas distribuidoras de dichos productos, que complementarían nuestro trabajo. En este sentido, futuras investigaciones deberán concentrar sus esfuerzos en explicar por qué en el cálculo de los precios nacionales de los hidrocarburos se utiliza como referencia el mercado de la Costa del Golfo de Estados Unidos a pesar de que estos productos son importados en su mayoría de otros mercados en donde rigen otros precios. A su vez, se debe revelar qué modelo o formula utilizan las empresas en el proceso de ajuste de precios, y en qué medida el mismo beneficia a las compañías (vía asimetría de precios) permitiéndoles incrementar sus ganancias. Las respuestas a estas preguntas deberán ofrecer suficientes insumos a las autoridades gubernamentales, diputados y redes de defensa del consumidor en torno a la discusión y pertinencia de adoptar nuevamente en Nicaragua el sistema de Precios de Paridad de Importación para regular los precios de los hidrocarburos.

\section{Agradecimientos}

Queremos agradecer en particular los comentarios y sugerencias de Carlos Narváez Silva. 


\section{Notas}

1 Esto cambió a mediados de los años 90 con la reforma al sector de hidrocarburos de la nación. Dicha reforma pretendía elevar los niveles de eficiencia y seguridad en el suministro del petróleo, atraer mayor inversión privada que se interesara por explorar y administrar los recursos energéticos, renovar la infraestructura de suministro de hidrocarburos y crear un marco legal apropiado.

2 Petróleo o crudo, es un término utilizado para referirse al petróleo sin procesar. El petróleo crudo es un combustible fósil, hecho naturalmente de plantas en descomposición y animales que vivían en mares antiguos hace millones de años. En muchos lugares el petróleo crudo se encuentra en el fondo del mar.

3 La naphta es un subproducto derivado del petróleo utilizado en el proceso de refinación.

4 Las importaciones de crudo y sus derivados provinieron de catorce países: Ecuador, México, Perú, Venezuela, Costa Rica, El Salvador, Guatemala, Honduras, Chile, Estados Unidos, Trinidad, West Indies, Bahamas y Ecuador.

5 Durante el año 2007 la refinería ESSO cubrió la demanda nacional de hidrocarburos en un 55.7\% con producción local.

6 Adicionalmente la ESSO cuenta con capacidad para almacenar hasta $187.8 \mathrm{mb}$ de crudo en las instalaciones de la refinería.

7 A diferencia del consumo, las ventas se refieren al producto que es comercializado por las cadenas distribuidoras.

8 Las estaciones de servicio se dividen en aquellas operadas directamente por la empresa y aquellas operadas por terceras partes a través de concesiones.

9 DNP es también el único operador en la Costa Atlántica, con terminales en Puerto Cabezas, El Bluff y Corn Island.

10 A raíz del embargo realizado a inicios de 2008 por el gobierno de Nicaragua al plantel de la ESSO en Corinto, ambas partes acordaron el traspaso de dicha infraestructura, por medio de una transacción de compra-venta, a la estatal PETRONIC. Con ello PETRONIC ahora dispone de capacidad propia para almacenar productos terminados importados desde Venezuela, no así estaciones de servicio para la venta directa al consumidor.

11 Ocasionalmente pueden darse compras inter-empresas a fin de abaratar costos de transporte o suplir caídas de inventarios, siempre y cuando las calidades satisfagan los requerimientos de cada empresa.

12 A diferencia de PETRONIC y DNP, la ESSO es la única empresa que importa gasolina regular.

13 La empresa estatal PETRONIC no realiza ventas directas a consumidores.

$14 \quad H=\sum_{i=1}^{n} S_{i}^{2}$

15 La empresa ESSO juega el principal rol en el establecimiento de los precios del mercado para SHELL, TEXACO y ESSO.

16 La elección de dichos productos deriva de su importancia dado que son los productos más consumidos por el parque automotor en Nicaragua a través de estaciones de servicio y clientes directos.

17 Para definir el número de rezagos utilizados en cada modelo se tomó en cuenta la prueba de t-student y el criterio de Akaike y Schwarz; utilizando la prueba empírica de prueba y error sobre dichos coeficientes estadísticos (ver anexo IV). 


\section{Anexo 1. Proceso de refinamiento del petróleo}

El petróleo resulta un insumo de mucha importancia para la elaboración de diversos productos, dado que contiene diferentes tipos de hidrocarburos ${ }^{1}$. Estos hidrocarburos tienen variadas propiedades, pesos y temperaturas de ebullición. Por medio del proceso de refinado (destilación fraccional), es posible separar los hidrocarburos heterogéneos (fracciones) presentes en el petróleo para elaborar productos útiles. El proceso de refinamiento del petróleo sigue los siguientes pasos:

1. El crudo es calentado a 600 grados Celsius hasta obtener vapor, que luego es introducido en una columna de destilación. En la medida en que los gases suben por la columna, éstos se enfrían y condensan a diferentes niveles/temperaturas. En cada nivel el producto es recogido por placas ubicadas dentro de la torre y posteriormente es enfriado aún más.

2. Luego del proceso de destilación, las refinerías deben de tratar las fracciones para remover cualquier tipo de impurezas. Primero una columna de ácido sulfúrico remueve hidrocarburos no saturados, compuestos de nitrógeno, oxigeno y residuos sólidos; luego una columna de absorción con agentes secantes remueve el agua, y por ultimo, un tratamiento de sulfuro e hidrógeno de sulfuro remueve componentes de sulfuro.

3. Una vez que las fracciones han sido tratadas, las refinerías las enfrían y luego mezclan para obtener diferentes productos, por ejemplo, gasolinas de diferentes octanajes, aceites lubricantes de varios pesos y grados, kerosén, jet-fuel, diesel y diferentes químicos para fabricar plásticos y polímeros.

Proceso de refinado del petróleo

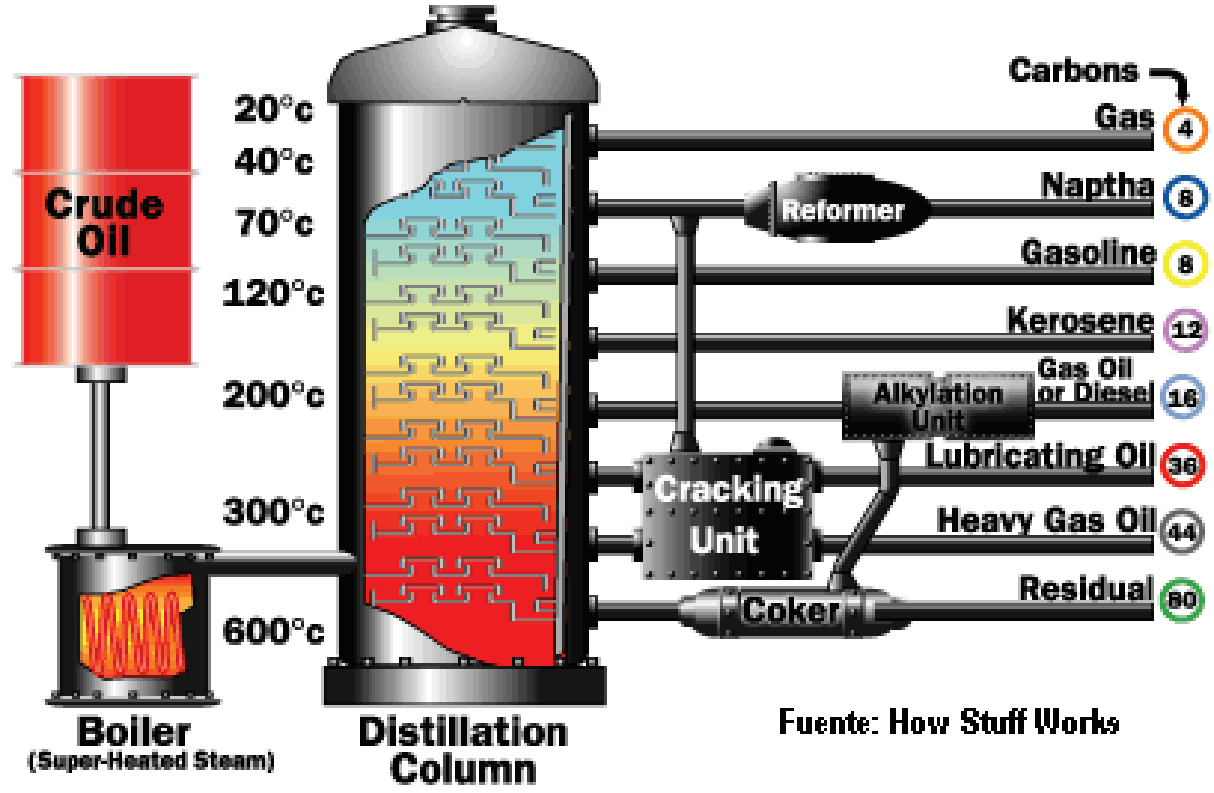

1 Los hidrocarburos son moléculas que contienen hidrógeno y carbono y vienen en varias longitudes y estructuras, de cadenas directas a cadenas en bifurcación a anillos. 


\section{Anexo 2. Resultados del modelo}

\section{Modelo diesel}

\begin{tabular}{|c|c|c|c|c|c|c|c|}
\hline \multicolumn{7}{|c|}{ Incremento precio internacional (a1) } & Decremento precio internacional (a2) \\
Constante \\
(a0)
\end{tabular}

Dependent Variable: DPND

Method: Least Squares

Date: 11/15/08 Time: 07:23

Sample(adjusted): 6141

Included observations: 136 after adjusting endpoints

Convergence achieved after 15 iterations

Backcast: -45

\begin{tabular}{|c|c|c|c|c|}
\hline Variable & Coefficient & Std. Error & t-Statistic & Prob. \\
\hline $\mathrm{C}$ & -0.000920 & 0.000272 & -3.383814 & 0.0010 \\
\hline APID & 0.025066 & 0.086993 & 0.288136 & 0.7737 \\
\hline BPID & -0.016752 & 0.088745 & -0.188766 & 0.8506 \\
\hline $\operatorname{APID}(-1)$ & 0.423890 & 0.123859 & 3.422369 & 0.0008 \\
\hline BPID(-1) & 0.574663 & 0.136285 & 4.216625 & 0.0000 \\
\hline APID(-2) & 0.458257 & 0.115870 & 3.954927 & 0.0001 \\
\hline BPID(-2) & 0.426912 & 0.096552 & 4.421577 & 0.0000 \\
\hline APID(-3) & 0.226035 & 0.077062 & 2.933134 & 0.0040 \\
\hline $\mathrm{AR}(1)$ & -0.056962 & 0.100225 & -0.568341 & 0.5708 \\
\hline MA(1) & -0.859948 & 0.046908 & -18.33256 & 0.0000 \\
\hline $\mathrm{MA}(10)$ & -0.128372 & 0.048680 & -2.637063 & 0.0094 \\
\hline R-squared & 0.764291 & \multicolumn{2}{|c|}{ Mean dependent var } & 0.002440 \\
\hline Adjusted R-squared & 0.745435 & \multicolumn{2}{|c|}{ S.D. dependent var } & 0.024228 \\
\hline S.E. of regression & 0.012224 & \multicolumn{2}{|c|}{ Akaike info criterion } & -5.893372 \\
\hline Sum squared resid & 0.018679 & \multicolumn{2}{|c|}{ Schwarz criterion } & -5.657790 \\
\hline Log likelihood & 411.7493 & \multicolumn{2}{|c|}{ F-statistic } & 40.53157 \\
\hline Durbin-Watson stat & 2.015335 & \multicolumn{2}{|c|}{ Prob(F-statistic) } & 0.000000 \\
\hline Inverted $\mathrm{AR}$ Roots & \multicolumn{4}{|c|}{-.06} \\
\hline \multirow[t]{3}{*}{ Inverted MA Roots } & .99 & $.77-.42 \mathrm{i}$ & $.77+.42 \mathrm{i}$ & $.33+.74 \mathrm{i}$ \\
\hline & $.33-.74 \mathrm{i}$ & $-.19-.75 \mathrm{i}$ & $-.19+.75 \mathrm{i}$ & $-.60+.47 \mathrm{i}$ \\
\hline & $-.60-.47 \mathrm{i}$ & & -.75 & \\
\hline
\end{tabular}


Modelo gasolina súper

\begin{tabular}{|c|c|c|c|c|c|c|c|c|}
\hline \multicolumn{9}{|c|}{ Incremento precio internacional (a1) } \\
& $\mathbf{a 1 , 1}$ & $\mathbf{a 1 , 2}$ & $\mathbf{a 1 , 3}$ & $\mathbf{a 1 , 4}$ & $\mathbf{a 2 , 0}$ & $\mathbf{a 2 , 1}$ & $\mathbf{a 2 , 2}$ & $\mathbf{a} 0$ \\
\hline $\begin{array}{c}\text { Gasolina } \\
\text { súper }\end{array}$ & 0.230359 & 0.581595 & 0.270868 & 0.152217 & 0.277409 & 0.531130 & 0.111975 & -0.000691 \\
\hline t-Student & 2.663542 & 6.415983 & 3.190196 & 1.757570 & 4.519727 & 9.310748 & 1.744671 & -0.373963 \\
\hline
\end{tabular}

Dependent Variable: DPNGS

Method: Least Squares

Date: 11/18/08 Time: 16:45

Sample(adjusted): 14141

Included observations: 128 after adjusting endpoints

Convergence achieved after 7 iterations

\begin{tabular}{ccccr}
\hline Variable & Coefficient & Std. Error & t-Statistic & Prob. \\
\hline C & -0.001976 & 0.001939 & -1.019297 & 0.3102 \\
BPIGS & -0.029777 & 0.056018 & -0.531560 & 0.5960 \\
APIGS(-1) & 0.282232 & 0.061200 & 4.611645 & 0.0000 \\
BPIGS(-1) & 0.257433 & 0.088364 & 2.913312 & 0.0043 \\
APIGS(-2) & 0.496334 & 0.060769 & 8.167571 & 0.0000 \\
BPIGS(-2) & 0.1434702 & 0.096263 & 5.554576 & 0.0000 \\
APIGS(-3) & 0.254581 & 0.067686 & 2.117643 & 0.0363 \\
APIGS(-4) & 0.152217 & 0.086606 & 1.757570 & 0.0814 \\
AR(5) & -0.214738 & 0.091718 & -2.341290 & 0.0209 \\
AR(8) & 0.193045 & 0.092088 & 2.096307 & 0.0382 \\
\hline \hline R-squared & 0.572886 & Mean dependent var & 0.002391 \\
Adjusted R-squared & 0.536381 & S.D. dependent var & 0.023754 \\
S.E. of regression & 0.016174 & Akaike info criterion & -5.328818 \\
Sum squared resid & 0.030607 & Schwarz criterion & -5.083721 \\
Log likelihood & 352.0443 & F-statistic & 15.69317 \\
Durbin-Watson stat & 2.012292 & Prob(F-statistic) & 0.000000 \\
\hline Inverted AR Roots & .75 & $.64-.58 \mathrm{i}$ & $.64+.58 \mathrm{i}$ & $-.06-.82 \mathrm{i}$ \\
& $-.06+.82 \mathrm{i}$ & -.51 -.58i & $-.51+.58 \mathrm{i}$ & -.87 \\
\hline
\end{tabular}


Anexo 3. Gráfica de series de tiempo para precios nacionales e internacionales
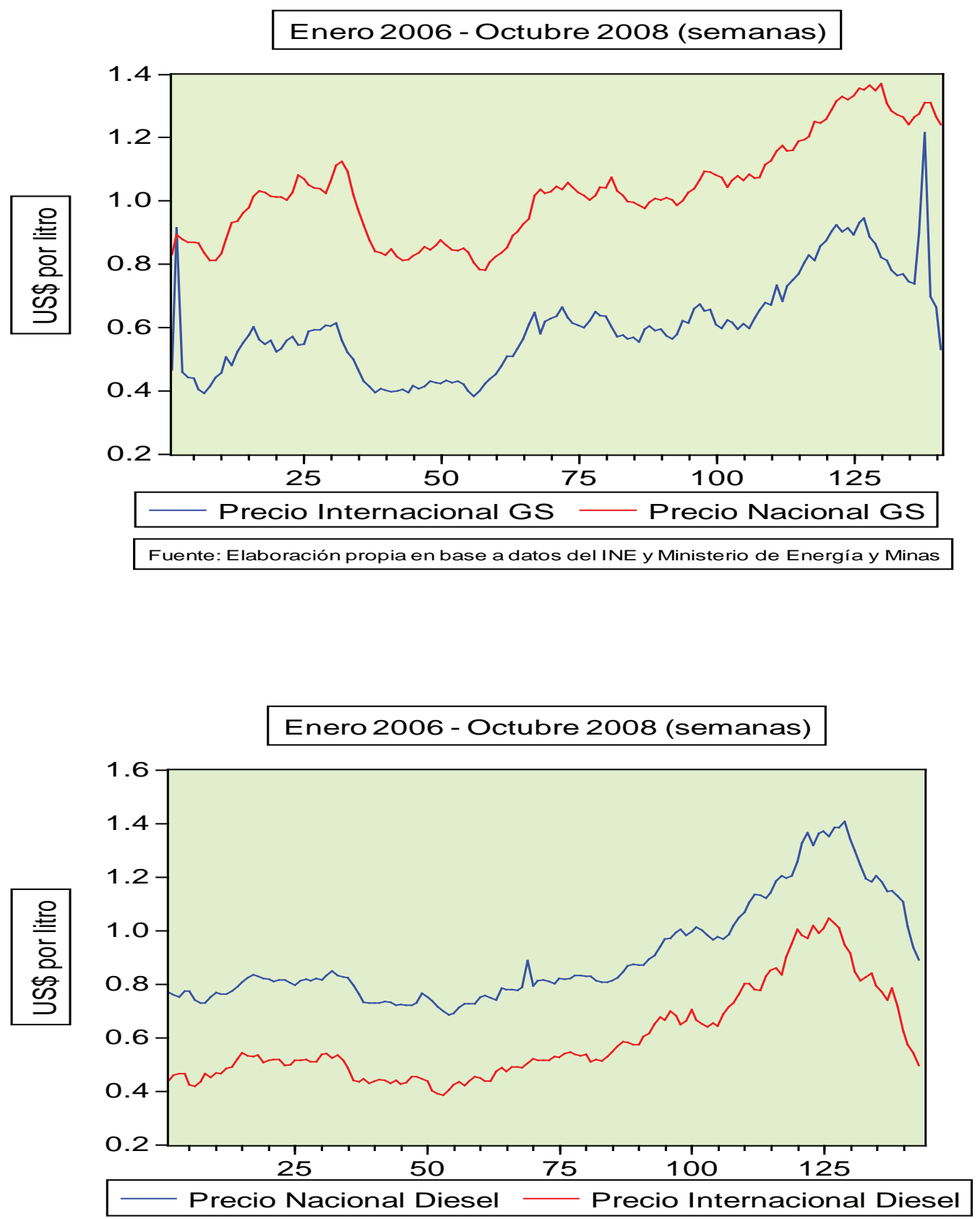

Fuente: Elaboración propia en base a datos del INE y Ministerio de Energía y Minas 


\section{Anexo 4. Prueba de raíz unitaria Augmented Dickey-Fuller}

Para que la serie de tiempo en ambos modelos sea estacionaria los valores del estadístico tau obtenidos deben ser mayores a los valores críticos de tau obtenidos de la prueba DickeyFuller en cada nivel de significancia $(1 \%, 5 \%, 10 \%)$.

Para comprobar las hipótesis se obtendrán los valores críticos de la prueba tau para cada nivel de significancia después de haber realizado cada una de las regresiones de ambos modelos. El resultado de la prueba de Dickey-Fuller es el siguiente:

Null Hypothesis: PNGS has a unit root

Exogenous: Constant

Lag Length: 1 (Automatic based on SIC, MAXLAG=13)

\begin{tabular}{lccc}
\hline \hline & & t-Statistic & Prob.* \\
\hline \hline Augmented Dickey-Fuller test statistic & -1.101585 & 0.7142 \\
\hline Test critical values: & $1 \%$ level & -3.477835 & \\
& $5 \%$ level & -2.882279 & \\
& $10 \%$ level & -2.577908 & \\
\hline \hline
\end{tabular}

*MacKinnon (1996) one-sided p-values.

Analizando los valores críticos tau de la prueba de Dickey-Fuller vemos que en ambos modelos la serie de tiempo es no estacionaria en todos los niveles de significancia porque -1.10 , el valor estadístico de tau, es inferior que todos los valores críticos.

Por esta razón, en el modelo se utilizan los precios nacionales en primera diferencia I(D) para corregir el problema de raíz unitaria de la serie de tiempo PNGS.

\section{Referencias bibliográficas}

BACON, R.W. (1991). "Rockets and Feathers: The Asymmetric Speed of Adjustment of UK Retail Gasoline Prices to Cost Changes." Energy Economics, Vol. 13, pp. 211-218.

BALKE, N.S.; BROWN, S.P.A. \& YÜCEL, M.K. (1998). "Crude Oil and Gasoline Prices: An Asymmetric Relationship?" Federal Reserve Bank of Dallas Economic Review, First Quarter, pp. 2-11.

BORENSTEIN, S.; CAMERON, A.C. \& GILBERT, R.J. (1997). "Do Gasoline Prices Respond Asymmetrically to Crude Oil Price Changes? “ The Quarterly Journal of Economics, Vol. 112, No. 1, pp. 305-339

BROWN, S.P.A. \& YÜCEL, M.K. (2000). "Gasoline and Crude Oil Prices: Why the Asymmetry?" Federal Reserve Bank of Dallas Economic and Financial Review, Third Quarter, pp. 23-29

KARRENBROCK, J.D. (1991). "The Behavior of Retail Gasoline Prices: Symmetric or Not?" Federal Reserve Bank of St. Louis Review Vol. 73, pp. 19-29. 
KINNUCAN, H.W. \& FORKER, O.D. (1987). "Asymmetry in Farm-Retail Price Transmission for Major Dairy Products”, American Journal of Agricultural Economics, Vol. 69, pp.285-292

MEYER, J. \& CRAMON-TAUBADEL, S.V. (2004). "Asymmetric Price Transmission: A Survey". Journal of Agricultural Economics, Volume 55, Number 3, pp. 581-61

MINISTERIO DE ENERGÍA Y MINAS (2008). Estadísticas de hidrocarburos, enero diciembre, 2007 preliminar. Mimeo.

SORUCO, M. J. (2004). "Asimetrías en la respuesta de los precios de la gasolina en el mercado chileno." Documento de Investigación I-156. Ilades/Georgetown University. 